\title{
Pengaruh Bahan Organik Dan Jamur Mikoriza Arbuskula Terhadap Harkat Tanah Pasir Pantai Selatan Yogyakarta Yang Menjadi Medium Pertumbuhan Jagung (Zea Mays)
}

\author{
Akhsin Zulkoni ${ }^{1}$, Dewi Rahyuni ${ }^{2}$, Nasirudin ${ }^{3}$ \\ 1,2,3 Institut Teknologi Yogyakarta \\ Surel: ${ }^{1}$ akhsinzul@gmail.com, ${ }^{2}$ dewirahyuni@gmail.com, ${ }^{3}$ nasir.canda@gmail.com
}

\begin{abstract}
ABSTRAK
Keberadaan tanah pasir pantai menyebabkan proses evaporasi dan degradasi oleh mikroba berlangsung cepat dan tanah pasir pantai miskin unsur hara. Lahan pasir pantai menjadi alternatif lahan pertanian, Penelitian bertujuan untuk mengetahui pengaruh bahan organik dan inokulasi Jamur Mikoriza Arbuskula (JMA) terhadap harkat tanah pasir pantai. Penelitian menggunakan rancangan acak kelompok lengkap dengan 3 ulangan. Faktor diuji adalah takaran bahan organic dari 0,20 , 40, dan 60 ton/ha; dan inokulasi JMA yaitu 0 dan 150 g/lubang tanam. Parameter yang dianalisis adalah $\mathrm{pH}\left(\mathrm{H}_{2} \mathrm{O}\right), \mathrm{C}$ organik, $\mathrm{N}$ total, $\mathrm{C} / \mathrm{N}, \mathrm{P}$ dan $\mathrm{K}$ tersedia. Data hasil penelitian dianalisis secara diskriptif dengan membandingkan Harkat sifat kimia tanah yang dikeluarkan oleh Balai Penelitian Tanah (2009), dan dianalisis menggunakan Anova $\alpha 1$ dan 5\%. Bila ada pengaruh yang nyata, dilanjutkan uji BNT $\alpha 5 \%$. Penambahan bahan organik ke dalam tanah mampu meningkatkan harkat sifat kimia tanah setelah masa inkubasi. Sedangkan harkat sifat kimia tanah setelah masa tanam jagung yang bermikoriza menurunkan dibanding dengan jagung tanpa JMA. Berdasar analisis keragaman, ternyata takaran bahan organik sebanyak 60 ton/ha merupakan perlakuan terbaik untuk meningkatkan kadar $\mathrm{C}$ organik, $\mathrm{N}$ total, $\mathrm{P}$ dan $\mathrm{K}$ tersedia serta KTK pada masa inkubasi. Setelah masa tanam jagung, $\mathrm{C}$ organik dan $\mathrm{N}$ total tertinggi tejadi pada tanah tanpa mikoriza dengan tambahan bahan organik 40 ton/ha, sedang untuk P dan K tersedia serta KTK terbaik pada tanah bermikoriza dengan tambahan bahan organik 40 ton/ha.
\end{abstract}

\section{Kata kunci}

Harkat tanah, bahan organik, JMA

\section{PENDAHULUAN}

Tanah pasir pantai merupakan jenis tanah yang tingkat kesuburannya sangat rendah, maka perlu dikelola agar memiliki produktivitas yang tinggi dengan cara menambahkan bahan pembenah tanah. Menurut Radjiman ${ }^{[1]}$, tanah pasir pantai adalah tanah yang didominasi oleh fraksi pasir (91\%) dengan klas tekstur pasiran.
Jumlah fraksi pasir yang tinggi menyebabkan luas permukaan jenis kecil; dan didominasi pori makro sehingga kemampuan mengikat dan menyediakan air $(10,8 \%)$ dan hara rendah. Ditambahkan oleh Syukur ${ }^{[2]}$, akibat dari oksigen yang melimpah dalam pori tanah menyebabkan pengeringan dan percepatan perombakan bahan organik, sehingga kesuburannya sangat rendah. 
Secara umum, bahan organik mengandung unsur-unsur $\mathrm{C}, \mathrm{H}, \mathrm{O}, \mathrm{N}, \mathrm{S}$ dan $\mathrm{P}$, yang merupakan sumber energi dan nutrisi bagi mikroba tanah, sehingga bisa meningkatkan proses dekomposisinya. Kandungan bahan organik tanah merupakan faktor kunci dalam menentukan kualitas dan produktivitas tanah karena fungsinya dalam mendaur nutrisi dan dalam memperbaiki fisik, kimia, dan biologi tanah. Hal ini dikarenakan keberadaan bahan organik dalam tanah berfungsi meningkatkan agregat dan aerasi tanah, serta memperbaiki drainase, menyediakan hara, meningkatkan kapasitas tukar kation, dan daya pegang air ${ }^{[3]}$.

Dekomposisi bahan organik menghasilkan humus yang memiliki luas permukaan dan kemampuan absorpsi lebih besar dari lempung. Agregasi tanah dapat memperbaiki tata udara dan air tanah yang baik, sehingga aktivitas mikroorganisme dapat optimal ${ }^{[2]}$. Kandungan karbon berkorelasi dengan kapasitas tukar kation tanah, kandungan $\mathrm{N}$ total tanah dan \% liat. Kandungan bahan organik (karbon organik) dalam tanah mencerminkan kualitas tanah yang langsung maupun tidak langsung berpengaruh pada kualitas tanah tersebut ${ }^{[4]}$. Penambahan bahan organik dapat meningkatkan ketersediaan air ${ }^{[5]}$. Selain itu, kehadiran pembenah tanah akan mengurangi evaporasi, menyeimbangkan aerasi tanah dengan penyediaan air serta menciptakan lingkungan yang baik bagi mikroorganisme ${ }^{[6]}$.

Mikoriza adalah bentuk asosiasi simbiosis antara jamur dan sistem perakaran tanaman tingkat tinggi ${ }^{[7]}$, serta $\operatorname{tanah}^{[8]}$, diantaranya adalah Jamur Mikoriza Arbuskula (JMA). Pada simbiosis ini JMA menghubungkan tanaman dengan tanah, dengan mengangkut hara mineral dari tanah ke tanaman dan senyawa karbon dari tanaman ke dalam tanah, oleh karena itu dipecah menjadi posfat organik yang kemudian dilepaskan ke sel tanaman inang ${ }^{[9]}$. JMA merupakan agensia nutrisi tanaman dan nutrisi tanah ${ }^{[10]}$. Jamur mikoriza terlibat dalam siklus dan dapat memanen unsur P. Phytat di dalam tanah merupakan sumber phosphat, dengan bantuan enzim fosfatase, phytat dapat dihidrolisis menjadi myoinosital, fosfor bebas dan mineral, sehingga ketersediaan fosfor dan mineral dalam tanah dapat terpenuhi ${ }^{[9]}$.

JMA berperan serta dalam pembentukan agregat tanah, bukan hanya miselium secara langsung mengikat partikel-partikel tanah, tetapi hifa-hifa jamur juga mampu mengikat tanah secara tidak langsung melalui produksi agensia pengikat berupa polisakarida amorf, menjadikan agregat tanah lebih longgar ${ }^{[10]}$. Madjid $^{[9]}$ menambahkan, Jamur merupakan suatu alat yang dapat memantapkan struktur tanah. Jamur mikoriza melalui jaringan hifa eksternal dapat memperbaiki dan memantapkan struktur tanah. Sekresi senyawa-senyawa polisakarida, asam organik dan lendir oleh jaringan hifa eksternal yang mampu mengikat butir-butir primer menjadi agregat mikro.

Sistem perakaran yang lebih menyebar dan lebih mendalam pada tanaman yang bermikoriza, meningkatkan efisiensi pengambilan dan penggunaan air ${ }^{[10]}$. Killham $^{[11]}$ menjelaskan bahwa jaringan hifa ekternal dari mikoriza akan memperluas bidang serapan air dan hara. Disamping itu ukuran hifa yang lebih halus dari bulu-bulu akar memungkinkan hifa bisa menyusup ke pori-pori tanah yang paling kecil (mikro) sehingga hifa bisa menyerap air pada kondisi kadar air tanah yang sangat rendah. Serapan air yang lebih besar oleh tanaman bermikoriza, juga membawa unsur hara yang mudah larut dan terbawa oleh aliran massa seperti $\mathrm{N}, \mathrm{K}$ dan $\mathrm{S}$ sehingga serapan unsur tersebut juga makin meningkat.

Hasil penelitian Nurmasyitah $\mathrm{dkk}^{[12]}$ menunjukkan bahwa dosis FMA berpengaruh sangat nyata terhadap $\mathrm{pH}$ tanah dan dosis FMA 40 g pot-1 merupakan perlakuan terbaik dengan $\mathrm{pH}$ tanah 6,35. Pemberian FMA mampu meningkatkan $\mathrm{pH}$ tanah dan memperbaiki tingkat kesuburan tanah. Hal ini dikarenakan dengan adanya aktifitas dan metabolisme FMA menghasilkan dan melepaskan senyawa-senyawa organik yang berperan dalam mengikat kation-kation logam penyebab kemasaman tanah sehingga $\mathrm{pH}$ meningkat. Sesuai dengan pendapat Tan ${ }^{[13]}$ senyawa-senyawa organik mampu mengikat kation-kation di dalam kompleks jerapan, 
sehingga konsentrasi kejenuhan basa menjadi tinggi, dan $\mathrm{pH}$ tanah menjadi naik. Pada pemberian dosis FMA $50 \mathrm{~g}$ pot $^{-1}$ tidak memberikan pengaruh yang bermakna untuk meningkatkan nilai $\mathrm{pH}$ tanah. Hal ini dikarenakan semakin banyak dosis FMA akan terjadi persaingan berkolonisasi pada akar tanaman kedelai.

Pemberian FMA mampu meningkatkan nilai N-total pada tanah Inceptisols Reuleut dan Andisols Saree dibandingkan tanpa FMA. Johansen $\mathrm{dkk}^{[14]}$ menyatakan bahwa kolonisasi FMA juga dapat meningkatkan nodulasi dan fiksasi $\mathrm{N}$ oleh rhizobium pada tanaman kacang-kacangan. FMA memiliki kemampuan untuk mengakumulasi dan memobilisasi $\mathrm{N}$ dari sumber ${ }^{[15]}$. Hasil penelitian menunjukkan bahwa secara mandiri jenis tanah mempengaruhi nilai $\mathrm{pH}$, P-tersedia dan KTK, jenis tanah dengan tingkat kesuburan tanah rendah yaitu tanah Ultisols Buket Rata. Pemberian dosis FMA mampu meningkatkan nilai $\mathrm{pH}$, P-tersedia dan KTK dibandingkan tanpa pemberian FMA. Interaksi antara jenis tanah dengan dosis FMA berpengaruh terhadap N-total tanah. Tanah Inceptisols Reuleut dengan pemberian dosis FMA $20 \mathrm{~g} \mathrm{pot}^{-1}$, Andisols Saree dengan pemberian dosis FMA $40 \mathrm{~g}$ pot $^{-1}$ mampu meningkatkan N-total tanah.

Hasil penelitian Nurmasyitah $\mathrm{dkk}^{[12]}$ menunjukkan bahwa dosis FMA berpengaruh nyata terhadap P- tersedia. Pemberian FMA meningkatkan P-tersedia tanah dibandingkan tanpa pemberian FMA. Hal ini memperlihatkan bahwa FMA mampu melepaskan unsur $\mathrm{P}$ yang difiksasi oleh logam-logam berat menjadi tersedia bagi tanaman. Penelitian Musfal ${ }^{[16]}$ menyatakan bahwa pemberian FMA pada tanaman jagung di tanah Inceptisols mampu meningkatkan Ptersedia 16,94 ppm.

Hasil secara mandiri menunjukkan bahwa dosis FMA berpengaruh nyata terhadap KTK tanah. Pemberian FMA mampu meningkatkan KTK tanah dibandingkan tanpa pemberian $\mathrm{FMA}^{[12]}$. Hal ini dikarenakan dengan pemberian FMA dapat mempengaruhi perubahan sifat fisika, kimia dan biologi. FMA mampu memperbaiki agregasi tanah dan meningkatkan $\mathrm{pH}$ tanah, sehingga KTK meningkat. Sesuai dengan Tisdall \& Oades ${ }^{[17]}$ menyatakan bahwa FMA berpengaruh terhadap sifat fisik tanah seperti agregasi tanah, persentase agregat tanah dengan ukuran $>2 \mathrm{~mm}$ lebih tinggi pada tanaman yang diinokulasi FMA dari pada tanpa FMA.

\section{METODE PENELITIAN}

Penelitian ini dilaksanakan menggunakan rancangan acak lengkap dengan tiga ulangan. Faktor yang diuji adalah takaran bahan organik, meliputi 0 (K0), 20 (K1), 40 (K2), dan 60 (K3) ton/ha; dan inokulasi JMA yaitu 0 (J0) dan 150 (J1) g/lubang tanam. Parameter yang dianalisis adalah $\mathrm{pH}\left(\mathrm{H}_{2} \mathrm{O}\right), \mathrm{C}$ organik, $\mathrm{N}$ total, $\mathrm{C} / \mathrm{N}, \mathrm{P}$ dan $\mathrm{K}$ tersedia, serta KTK. Data hasil penelitian dianalisis secara diskriptif dengan membandingkan Harkat sifat kimia tanah yang dikeluarkan oleh Balai Penelitian Tanah ${ }^{[18]}$, dan Anova $\alpha 1$ dan 5\%, bila ada pengaruh yang nyata, dilanjutkan uji BNT $\alpha 5 \%{ }^{[19]}$.

Tahap awal adalah pencampuran bahan organik dilakukan secara merata ke dalam tanah. lalu disiram hingga kapasitas lapangan. Didiamkan selama 14 hari untuk masa inkubasi. Selama masa inkubasi kadar lengas dipertahankan pada kondisi lapangan dengan cara penyiraman. Pada perlakuan inokulasi JMA, maka pada tiap lubang tanam dibubuhkan JMA sebanyak 150 g. Setelah itu, baru ditanam bibit jagung. Pertumbuhan tanaman sampai masa generatif. Analisis tanah dilakukan pada tanah awal, masa inkubasi dan setelah masa tanam jagung.

\section{HASIL DAN PEMBAHASAN Karakteristik Tanah Awal}

Tanah pasir pantai Selatan Yogyakarta memiliki tingkat kesuburan yang sangat rendah, sehingga tidak layak sebagai medium pertumbuhan tanaman. Hasil selengkapnya dituangkan pada Tabel 1 
Tabel 1. Karakteristik tanah awal pasir pantai Selatan Yogyakarta

\begin{tabular}{clccc}
\hline No & \multicolumn{1}{c}{ Parameter } & Satuan & Nilai & Kriteria $*$ \\
\hline 1 & C organik & $\%$ & 0,040 & Sangat rendah \\
2 & N total & $\%$ & 0,0851 & Sangat rendah \\
3 & $\mathrm{C} / \mathrm{N}$ & - & 0,47 & Sangat rendah \\
4 & $\mathrm{P}_{2} \mathrm{O}_{5}$ & $\mathrm{me} / 100 \mathrm{~g}$ & 0.06 & Sangat rendah \\
5 & $\mathrm{~K}_{2} \mathrm{O}$ & $\mathrm{me} / 100 \mathrm{~g}$ & 0,10 & rendah \\
6 & $\mathrm{KTK}$ & $\mathrm{me} / 100 \mathrm{~g}$ & 2,20 & Sangat rendah \\
7 & $\mathrm{pH}\left(\mathrm{H}_{2} \mathrm{O}\right)$ & - & 7 & Netral \\
\hline
\end{tabular}

Keterangan *: Balai Penelitian Tanah ${ }^{[18]}$

Tampak pada Tabel 1, sebagian besar sifat kimia tanahnya memiliki harkat sangat rendah, kecuali $\mathrm{K}$ tersedia yang berharkat rendah. Hal ini sesuai dengan pendapat Radjiman $\mathrm{dkk}^{[1]}$, bahwa tanah pasir pantai didominasi oleh fraksi pasir (91\%) dengan klas tekstur pasiran. Jumlah fraksi pasir yang tinggi menyebabkan luas permukaan jenis kecil dan didominasi pori makro sehingga kemampuan mengikat dan menyediakan air $(10,8 \%)$ dan hara rendah. Syukur ${ }^{[2]}$ menyampaikan pendapat, akibat dari oksigen yang melimpah dalam pori tanah menyebabkan pengeringan dan percepatan perombakan bahan organik, menyebabkan kesuburannya sangat rendah.

\section{Sifat Kimia Tanah Setelah masa inkubasi}

Pemberian bahan organik pada berbagai taraf yang dicampur secara merata ke dalam tanah telah merubah nilai sifat kimianya. Hasil keseluruhan ditunjukkan dalam Tabel 2. Pada Tabel 2 terlihat jelas bahwa harkat tanah mengalami peningkatan setelah dicampur dengan bahan organik dan diikubasikan selama 14 hari. Nilai $\mathrm{pH}$ pada seluruh perlakuan berada pada kondisi netral, yaitu antara 7 hingga 7,1 . Menurut $\operatorname{Tan}^{[13]}$ senyawasenyawa organik, termasuk senyawa antara hasil dekomposisi bahan organik oleh mikroorganisme mampu mengikat kationkation di dalam kompleks jerapan, sehingga konsentrasi kejenuhan basa menjadi tinggi, dan $\mathrm{pH}$ tanah menjadi naik.

Tabel 2. Harkat sifat kimia tanah pasir pantai setelah masa inkubasi dengan bahan organik

\begin{tabular}{llcccccccc}
\hline \multirow{2}{*}{ No } & \multirow{2}{*}{ Parameter } & \multicolumn{9}{c}{ Takaran bahan organik (ton/ha) } \\
\cline { 3 - 9 } & & \multicolumn{3}{c}{0} & \multicolumn{3}{c}{20} & 40 & \multicolumn{2}{c}{60} \\
\cline { 2 - 8 } & & Nilai & Harkat* & Nilai & Harkat* & Nilai & Harkat* & Nilai & Harkat* \\
\hline 1 & $\mathrm{pH}\left(\mathrm{H}_{2} \mathrm{O}\right)$ & $7,03 \mathrm{a}$ & Netral & $7,00 \mathrm{a}$ & Netral & $7,10 \mathrm{a}$ & Netral & $7,00 \mathrm{a}$ & Netral \\
2 & $\mathrm{C}$ organic (\%) & $0,451 \mathrm{a}$ & $\mathrm{SR}$ & $2,191 \mathrm{~b}$ & $\mathrm{~S}$ & $4,032 \mathrm{c}$ & $\mathrm{T}$ & $4,505 \mathrm{~d}$ & $\mathrm{~T}$ \\
3 & $\mathrm{~N}$ total $(\%)$ & $0,081 \mathrm{a}$ & $\mathrm{SR}$ & $0,273 \mathrm{~b}$ & $\mathrm{~S}$ & $0,481 \mathrm{c}$ & $\mathrm{S}$ & $0,509 \mathrm{~d}$ & $\mathrm{~S}$ \\
4 & $\mathrm{C} / \mathrm{N}$ & $5,56 \mathrm{a}$ & $\mathrm{R}$ & $8,03 \mathrm{~b}$ & $\mathrm{R}$ & $8,38 \mathrm{~b}$ & $\mathrm{R}$ & $8,85 \mathrm{~b}$ & $\mathrm{R}$ \\
5 & $\mathrm{P}_{2} \mathrm{O}_{5}(\mathrm{ppm})$ & $0,08 \mathrm{a}$ & $\mathrm{SR}$ & $2,17 \mathrm{a}$ & $\mathrm{SR}$ & $5,81 \mathrm{~b}$ & $\mathrm{R}$ & $6,01 \mathrm{~b}$ & $\mathrm{R}$ \\
6 & $\mathrm{~K}_{2} \mathrm{O}(\mathrm{ppm})$ & $0,14 \mathrm{a}$ & $\mathrm{SR}$ & $0,66 \mathrm{a}$ & $\mathrm{SR}$ & $0,82 \mathrm{~b}$ & $\mathrm{SR}$ & $0,86 \mathrm{c}$ & $\mathrm{SR}$ \\
7 & $\mathrm{KTK}(\mathrm{ppm})$ & $2,21 \mathrm{a}$ & $\mathrm{SR}$ & $2,71 \mathrm{~b}$ & $\mathrm{SR}$ & $3,25 \mathrm{c}$ & $\mathrm{SR}$ & $3,56 \mathrm{~d}$ & $\mathrm{SR}$ \\
\hline
\end{tabular}

Keterangan: 1) *: Balai Penelitian Tanah ${ }^{[18]}$, SR: sangat rendah, R: rendah, S: sedang, T: tinggi 2) Huruf kecil yang sama di belakang nilai rata-rata pada baris yang sama menunjukkan tidak ada beda antara satu dengan yang lain berdasar uji BNT $\alpha 5 \%$.

Pada pemberian bahan organik sebanyak 40 ton/ha sudah bisa menaikkan harkat sifat kimia tanah menjadi tinngi dari semula yang sangat rendah. Demikian juga untuk $\mathrm{N}$ total bisa naik menjadi sedang dari awal yang berharkat sangat rendah. Dalam hal ini Millner dan Kaufman ${ }^{[3]}$ menjelaskan bahwa secara umum bahan organik mengandung unsur-unsur $\mathrm{C}, \mathrm{H}, \mathrm{O}, \mathrm{N}, \mathrm{S}$ dan $\mathrm{P}$, sehingga keberadaanya di dalam tanah sangat nyata menambah unsur $\mathrm{C}$ dan N. Penambahan bahan organik dapat meningkatkan ketersediaan air $^{[5]}$. Selain itu, kehadiran pembenah tanah akan mengurangi evaporasi, 
menyeimbangkan aerasi tanah dengan penyediaan air serta menciptakan lingkungan yang baik bagi mikroorganisme ${ }^{[6]}$, sehingga mendukung proses degradasi bahan organik menjadi senyawa yang sederhana.Namun ketersediaan unsur $\mathrm{P}$ dan $\mathrm{K}$ masih berada pada harkat sangat rendah, artinya tidak ada perubahan dari semula. Kehadiran oksigen yang melimpah melimpah dalam pori tanah menyebabkan pengeringan dan percepatan perombakan bahan organik, sehingga kesuburannya sangat rendah ${ }^{[2]}$.

Menurut analisis keragaman, ternyata bahan organik berpengaruh sangat nyata terhadap nilai sifat kimia tanah pasir pantai setelah masa inkubasi. Tabel 2 memperlihatkan bahwa berdasar uji BNT $\alpha$ $5 \%$, taraf bahan organik sebanyak 60 ton/ha yang berhasil meningkatkan beberapa parameter. Nilai $\mathrm{C}$ organik, $\mathrm{N}$ total, $\mathrm{K}$ tersedia dan KTK mengalami penambahan berturutturut sebesar 4,054 \%. 0,428 \%; 0,72 ppm dan 1,35 ppm dari kontrol. Keadaan ini sesuai dengan pendapat Supriyadi ${ }^{[4]}$ yang mengemukakan bahwa kandungan karbon berkorelasi dengan kandungan $\mathrm{N}$ total dan KTK. Hal ini dikarenakan keberadaan bahan organik dalam tanah berfungsi meningkatkan agregat dan aerasi tanah, serta memperbaiki drainase, menyediakan hara, meningkatkan kapasitas tukar kation, dan daya pegang air ${ }^{[3]}$. Agregasi tanah akan memperbaiki tata udara dan air tanah dengan baik, sehingga aktivitas mikroorganisme dapat optimal ${ }^{[2]}$. Dekomposisi bahan organik menghasilkan humus yang memiliki luas permukaan dan kemampuan absorpsi lebih besar dari lempung. Nilai $\mathrm{P}$ tersedia dan $\mathrm{C} / \mathrm{N}$ pada takaran bahan organik seberat 60 ton/ha tidak beda nyata dengan pemberian bahan organik 40 ton/ha.

Peningkatan harkat sifat kimia tanah oleh bahan organik menjadi dasar untuk pemanfaatan tanah pasir pantai sebagai medium pertumbuhan tanaman jagung. Kandungan bahan organik tanah merupakan faktor kunci dalam menentukan kualitas dan produktivitas tanah karena fungsinya dalam mendaur nutrisi dan dalam memperbaiki fisik, kimia, dan biologi tanah.

\section{Sifat Kimia Tanah Setelah Masa Penanaman Jagung}

Selain penambahan bahan organik, juga dilakukan inokulasi JMA ke dalam tanah pasir pantai yang menjadi medium pertumbuhan jagung. Sifat kimia tanah pasir pantai setelah selesai masa tanam jagung disajikan dalam Tabel 3.

Tabel 3. Harkat sifat kimia tanah pasir pantai setelah masa penanaman jagung

\begin{tabular}{|c|c|c|c|c|c|c|c|c|c|c|c|c|}
\hline \multirow{2}{*}{$\begin{array}{l}\text { Perla- } \\
\text { kuan }\end{array}$} & \multicolumn{2}{|c|}{$\mathrm{pH}$} & \multicolumn{2}{|c|}{$\mathrm{C}$ organik (\%) } & \multicolumn{2}{|c|}{$\mathrm{N}$ total $(\%)$} & \multicolumn{2}{|c|}{$\mathrm{P}_{2} \mathrm{O}_{5}(\mathrm{ppm})$} & \multicolumn{2}{|c|}{$\mathrm{K}_{2} \mathrm{O}$ (ppm) } & \multicolumn{2}{|c|}{ KTK } \\
\hline & Nilai & Harkat & Nilai & Harkat & Nilai & Harkat & Nilai & Harkat & Nilai & Harkat & Nilai & Harkat \\
\hline J0K0 & $7,00 \mathrm{a}$ & netral & $0.64 a b$ & SR & $0.0314 c$ & SR & $0.26 \mathrm{a}$ & SR & $0.19 \mathrm{a}$ & SR & $0.19 \mathrm{a}$ & SR \\
\hline J0K1 & $7,10 \mathrm{a}$ & netral & $1.91 \mathrm{c}$ & $\mathrm{R}$ & $0.0293 \mathrm{c}$ & SR & $0.42 \mathrm{~b}$ & SR & $0.35 \mathrm{a}$ & SR & $0.35 \mathrm{a}$ & SR \\
\hline J0K2 & $7,03 \mathrm{a}$ & netral & $3.10 \mathrm{~d}$ & $\mathrm{~T}$ & $0.0316 \mathrm{~d}$ & SR & $0.52 \mathrm{c}$ & SR & $0.61 \mathrm{ab}$ & SR & $0.61 \mathrm{c}$ & SR \\
\hline J0K3 & $7,06 \mathrm{a}$ & netral & $3.32 \mathrm{~d}$ & $\mathrm{~T}$ & $0.0185 b$ & SR & $0.57 \mathrm{~cd}$ & SR & $0.66 \mathrm{c}$ & SR & $0.66 \mathrm{~d}$ & SR \\
\hline JIK0 & $7,00 \mathrm{a}$ & netral & $0.15 \mathrm{a}$ & SR & $0.0075 \mathrm{a}$ & SR & $0.29 \mathrm{a}$ & SR & $0.33 \mathrm{a}$ & SR & $0.33 \mathrm{a}$ & SR \\
\hline JIK1 & $7,10 \mathrm{a}$ & netral & $1.18 \mathrm{~b}$ & $\mathrm{R}$ & $0.0161 \mathrm{ab}$ & SR & $0.51 b c$ & SR & $0.62 b c$ & SR & $0.62 \mathrm{~cd}$ & SR \\
\hline JIK2 & $7,20 \mathrm{a}$ & netral & $1.79 \mathrm{c}$ & $\mathrm{R}$ & $0.0171 \mathrm{ab}$ & SR & $0.66 \mathrm{de}$ & SR & $0.72 \mathrm{~d}$ & SR & $0.72 \mathrm{e}$ & SR \\
\hline JIK3 & $7,06 \mathrm{a}$ & netral & $1.84 \mathrm{c}$ & $\mathrm{R}$ & $0.0185 b$ & SR & $0.71 \mathrm{e}$ & SR & $0.75 \mathrm{~d}$ & SR & $0.75 \mathrm{e}$ & SR \\
\hline
\end{tabular}

Keterangan: 1) Harkat: Balai Penelitian Tanah ${ }^{[18]}$; SR: sangat rendah; R: rendah; T: tinggi

2) Huruf kecil yang sama di belakang nilai rata-rata pada kolom yang sama menunjukkan tidak ada beda antara satu dengan yang lain berdasar uji BNT $\alpha$ 5\%.

Tabel 3 menunjukkan kondisi sifat kimia tanah setelah masa tanam jagung. Harkat sifat kimia tanah mengalami perubahan bila dibandingkan dengan harkatnya setelah masa inkubasi tanah. Pada umumnya sifat kimia tanah pasir pantai setelah masa tanam jagung berada pada harkat yang sangat rendah. Hal ini menggambarkan tingkat penyerapan unsur hara oleh takar tanaman, seperti yang disampaikan oleh Madjid ${ }^{[9]}$, pada simbiosis ini JMA menghubungkan tanaman dengan tanah, dengan mengangkut hara mineral dari 
tanah ke tanaman dan senyawa karbon dari tanaman ke dalam tanah, selanjutnya dipecah menjadi posfat organik yang kemudian dilepaskan ke sel tanaman inang.

Pada perlakuan inokulasi JMA, sifat kimia tanahnya lebih rendah dari kontrol. Hal ini membuktikan bahwa tanaman yang bermikoriza daerah penyerapannya lebih luas dibanding kontrol. Dalam hal ini Kabirun ${ }^{[10]}$ menjelaskan bahwa sistem perakaran yang lebih menyebar dan lebih mendalam pada tanaman yang bermikoriza, dapat meningkatkan efisiensi pengambilan dan penggunaan air ${ }^{[10]}$. Ditambahkan oleh Killham ${ }^{[11]}$ bahwa jaringan hifa ekternal dari mikoriza akan memperluas bidang serapan air dan hara. Disamping itu ukuran hifa yang lebih halus dari bulu-bulu akar memungkinkan hifa bisa menyusup ke poripori tanah yang paling kecil (mikro) sehingga hifa bisa menyerap air pada kondisi kadar air tanah yang sangat rendah. Serapan air yang lebih besar oleh tanaman bermikoriza, juga membawa unsur hara yang mudah larut dan terbawa oleh aliran massa seperti N, K dan S sehingga serapan unsur tersebut juga makin meningkat.

Kandungan $\mathrm{C}$ organik masih berada dalam kriteria yang lebih tinggi daripada $\mathrm{N}$ total. Selama masa pertumbuhan jagung, selain berlangsung proses penyerapan unsur C, hifa eksternal JMA memproduksi sekresi yang berupa senyawa-senyawa polisakarida, asam organik dan lender ${ }^{[9]}$, yang dapat menambah C organik tanah. Madjid ${ }^{[9]}$ menambahkan, jaringan hifa eksternal jamur mengeluarkan sekresi senyawa-senyawa polisakarida, asam organik dan lendir oleh jaringan hifa eksternal yang mampu mengikat butir-butir primer menjadi agregat mikro.

$\mathrm{pH}$ tanah setelah masa tanam berada pada nilai yang netral. Hasil penelitian Nurmasyitah $\mathrm{dkk}^{[12]}$ menunjukkan bahwa JMA berpengaruh sangat nyata terhadap $\mathrm{pH}$ tanah dan dosis FMA 40 g/pot merupakan perlakuan terbaik dengan $\mathrm{pH}$ tanah 6,35. Pemberian FMA mampu meningkatkan $\mathrm{pH}$ tanah dan memperbaiki tingkat kesuburan tanah. Hal ini dikarenakan dengan adanya aktifitas dan metabolisme FMA menghasilkan dan melepaskan senyawa-senyawa organik yang berperan dalam mengikat kation-kation logam penyebab kemasaman tanah sehingga $\mathrm{pH}$ meningkat.

Peningkatan takaran bahan organik tidak diiukti oleh nilai $\mathrm{pH}$..Keadaan ini sama dengan hasil penelitian Nurmasyitah $\mathrm{dkk}^{[12]}$ yang memperoleh data bahwa dosis FMA 50 g pot-1 tidak memberikan pengaruh yang bermakna untuk meningkatkan nilai $\mathrm{pH}$ tanah. Hal ini dikarenakan semakin banyak dosis FMA akan terjadi persaingan berkolonisasi pada akar tanaman kedelai.

Berdasar analisis keragaman, kandungan $\mathrm{C}$ organik dan $\mathrm{N}$ total dalam tanah setelah masa tanam pada kontrol lebih baik daripada tanah yang digunakan untuk tanaman jagung yang bermikoriza. Pada pemberian bahan organik 40 ton/ha tanpa JMA, ternyata memiliki C organik lebih tinggi dibanding dengan tanaman yang bermikoriza, yaitu 3,10\%. Demikian juga dengan $\mathrm{N}$ total. Tanah kontrol justru memiliki kadar $\mathrm{N}$ total lebih tinggi daripada tanah yang bermikoriza (Tabel 3). Johansen $\mathrm{dkk}^{[14]}$ menyatakan bahwa kolonisasi JMA juga dapat meningkatkan nodulasi dan fiksasi $\mathrm{N}$ oleh rhizobium pada tanaman kacangkacangan. FMA memiliki kemampuan untuk mengakumulasi dan memobilisasi $\mathrm{N}$ dari sumber organik $^{[15] \text {. }}$

Berbeda dengan $\mathrm{P}$ dan $\mathrm{K}$ tersedia serta KTK (Tabel 3), maka tanah yang berfungsi sebagai medium pertumbuhan tanaman jagung yang bermikoriza justru masih memiliki kadar yang tinggi. Hasil penelitian Nurmasyitah $\mathrm{dkk}^{[12]}$ menunjukkan bahwa dosis JMA berpengaruh nyata terhadap P-

tersedia. Pemberian FMA meningkatkan Ptersedia tanah dibandingkan tanpa pemberian JMA. Hal ini memperlihatkan bahwa JMA mampu melepaskan unsur $\mathrm{P}$ yang difiksasi oleh logam-logam berat menjadi tersedia bagi tanaman. Penelitian Musfal ${ }^{[16]}$ menyatakan bahwa pemberian JMA pada tanaman jagung di tanah Inceptisols mampu meningkatkan Ptersedia 16,94 ppm. Hasil secara mandiri menunjukkan bahwa dosis JMA berpengaruh nyata terhadap KTK tanah.

Pemberian JMA mampu meningkatkan KTK tanah dibandingkan tanpa pemberian $\mathrm{JMA}^{[12]}$. Hal ini dikarenakan dengan 
pemberian JMA dapat mempengaruhi perubahan sifat fisika, kimia dan biologi. JMA mampu memperbaiki agregasi tanah dan meningkatkan $\mathrm{pH}$ tanah, sehingga KTK meningkat. Sesuai dengan Tisdall \& Oades ${ }^{[17]}$ menyatakan bahwa JMA berpengaruh terhadap sifat fisik tanah seperti agregasi tanah, persentase agregat tanah dengan ukuran $>2 \mathrm{~mm}$ lebih tinggi pada tanaman yang diinokulasi JMA dari pada tanpa JMA.

\section{KESIMPULAN}

1. Penambahan bahan organik ke dalam tanah mampu meningkatkan harkat sifat kimia tanah setelah masa inkubasi. Sedangkan perlakuan JMA menurunkan harkat sifat kimia tanah setelah masa tanam jagung dibanding dengan tanah tanpa JMA.

2. Takaran bahan organik sebanyak 60 ton/ha merupakan perlakuan terbaik untuk meningkatkan kadar $\mathrm{C}$ organik, $\mathrm{N}$ total, $\mathrm{P}$ dan $\mathrm{K}$ tersedia serta KTK pada masa inkubasi. Setelah masa tanam jagung, C organik dan $\mathrm{N}$ total tertinggi tejadi pada tanah tanpa mikoriza dengan tambahan bahan organik 40 ton/ha, sedang untuk $\mathrm{P}$ dan $\mathrm{K}$ tersedia serta KTK terbaik pada tanah bermikoriza dengan tambahan bahan organik 40 ton/ha.

\section{SARAN}

Perlu dilakukan penelitian tentang serapan hara oleh tanaman jagung sehingga bisa diketahui neraca keharaan di dalam tanah pasir pantai.

\section{UCAPAN TERIMA KASIH}

Ucapan terima kasih kami sampaikan kepada Bapak Direktur Riset dan Pengabdian Masyarakat Direktorat Jenderal Penguatan Riset dan Pengembangan Kementerian Riset Teknologi dan Pendidikan Tinggi yang telah mendanai penelitian terapan kami sehingga jurnal ini dapat terwujud.

\section{REFERENSI}

[1] Radjiman, Y., Prapto, E. S, Hanudin, E., 2008, Pengaruh Pembenah Tanah Terhadap Sifat Fisika Tanah Dan Hasil Bawang Merah Pada Lahan Pasir Pantai
Bugel, Kabupaten Kulon Progo. AGRIN, 12 (1), 67-77.

[2] Syukur, A., 2005, Pengaruh Pemberian Bahan Organikterhadap Sifat-Sifat Tanah Dan Pertumbuhan Caisim Di Tanah Pasirpantai. Jurnal Ilmu Tanah dan Lingkungan, V (1).

[3] Millner,P.D., Kaufman, D. D., 2005, Soil Organic Matter Dynamic And Microbial Interactions. Agricultural Research Service US. Department of Agriculture, Beltsville, Maryland, USA.

[4] Supriyadi, S., 2008, Kandungan bahan organik sebagai dasar pengelolaan tanah di lahan kering Madura. EMBRYO, 5 (2).

[5] Puspowardoyo, S., 2005, Pengaruh Pemberian Daun Krenyu (Chromolaena $s p$.) dan Jerami Kering Sebagai Pupuk Organik Terhadap Hasil Budidaya Tanaman Bawang Merah, Jagung Manis Dan Kacang Tanah Di Lahan Pasir. Jurnal Sain dan Teknolog.

[6] Mashudi, 2007, Budidaya Terong. Jakarta: Azka Press.

[7] Marschner, H., 1991, Mechanisms Of Adaptation Of Plant To Acid Soil. Plant and Soil. 134, 1-20.

[8] Sieverding, E., 1991, Vesicular Arbuscular Mycorrhiza Management In Tropical Agrosystem. Deutsche Gesellschaft fur technische Zusammerarbeit (GTZ) G mb N. Dag Hammavskjola - Veg $1+2$.

[9] Madjid, A., 2009, Pengelolaan Kesuburan Tanah Mineral Masam untuk Pertanian. Makalah Pengelolaan Kesuburan Tanah, Program Studi Ilmu Tanaman, Program Magister (S2), Program Pascasarjana, Universitas Sriwijaya, Palembang.

[10] Kabirun, S., 2004, Peranan Mikoriza Arbuscula Pada Pertanian Berkelanjutan. Universitas Gadjah Mada Yogyakarta.

[11]Killham, K., 1994, Soil Ecology. Cambridge University Press.

[12]Nurmasyitah, Syafrudin, Sayuthi, M., 2013, Pengaruh Jenis Tanah dan Dosis Fungi Mikoriza Arbuskular pada Tanaman Kedelai Terhadap Sifat Kimia Tanah. Jurnal Agrista, 17 (3). 
[13]Tan, K. H., 1995, Dasar-Dasar Kimia Tanah. Gadjah Mada University Press.

[14] Johansen, A., I. Jakobsen, Jensen, E. S., 1992, Hyphal Transport Of 15 NLabelled Nitrogen By A Vesicular Arbuscula Rmycorrhizal Fungus And Its Effect Ondepletion Of Inorganic Soil N. New Phytol, 122, 281-282.

[15] Barrett, G., Campbell, C.D., Fitter, A. H., Hodge, A., 2011, The arbuscula rmycorrhizal fungus Glomus hoi cancapture and transfer nitrogen fromorganic patches to its associated hostplant at low temperature. Appl Soil Ecol, 48, 102-105.

[16]Musfal, 2008, Efektifitas Cendawan Mikoriza Arbuskular (CMA) terhadap Pemberian Pupuk Spesifik Lokasi Tanaman Jagung Pada Tanah Inceptisol. Tesis. Sekolah Pasca sarjana Universitas Sumatera Utara, Medan.
[17] Tisdall, J. M., Oades, J. M., 1979, Stabilisation of soil aggregates by theroot systems of ryegrass. Australian Journal of Soil Research, 17, 429-441.

[18]Balai Penelitian Tanah, 2009, Analisis kimia tanah, tanaman, air dan pupuk. Balai Besar Litbang Sumber daya Lahan dan Pertanian, Badan Penelitan Pertanian.dan Pengembangan Pertanian. Departemen Pertanian.

[19]Gomez, K. A., Gomez, A. A., 2005, Prosedur Statistik untuk Penelitian Pertanian. Alih bahasa: E. Sjamsuddin and J.S. Baharsjah. University Indonesia Press, Jakarta. 